\title{
The Continuous Sampling Plan for Two Production Lines: The CSP-2L
}

\author{
PANNARAT GUAYJARERNPANISHK, TAWUN REMSUNGNEN \\ Faculty of Interdisciplinary Studies \\ Nong Khai Campus, Khon Kaen University \\ Tambon Nong Kom Koh, Muang District, Nong Khai, 43000 \\ THAILAND
}

\begin{abstract}
This paper presents the CSP-2L continuous sampling plan, which is designed for product inspection on two independent production lines at the same time. The purpose of the CSP-2L is to improve the CSP-1-2L in order to reduce the number of defective products that have passed without being inspected during the temporary inspection stop, so the quality of the products is better. Therefore, if the manufacturer who uses the CSP-2L plan to inspect the production lines then resulting in higher quality of the products than the CSP-1-2L. This presentation includes the product inspection procedures and the formulas for performance measures such as average total fraction inspected (ATFI), average total outgoing quality $(A T O Q)$, and average total outgoing quality limit $(A T O Q L)$ which are carried out using a Markov chain. The formulas for performance measures of the CSP-2L have been tested to be accurate. When defined, the probability of a unit produced by the process being nonconforming of line 1 and line 2 are equal ( $p_{1}=p_{2}=p=0.005,0.015$ and 0.035$)$, the clearance number of line 1 and line 2 are equal $\left(i_{1}=i_{2}=10,20,30,40\right.$ and 50), the sampling fraction of line 1 and line 2 are equal $\left(f_{1}=f_{2}=1 / 2\right.$ and 1/3) and the number of units to be found when inspection of line 1 and line 2 are in the phase of sampling inspection at the same time ( $m=i_{1}$ and $\left.2 i_{1}\right)$. Moreover, the ATOQ values from the CSP-2L and the CSP-1-2L plans were compared. The results showed that, the formulas for performance measures are accurate and in the case of $p$, the levels are low and moderate, the $A T O Q$ of the CSP-2L are less than those of the CSP-1-2L in all cases. But in the case of $p$ is at a high level, the ATOQ of the CSP-2L is less than those of the CSP-1-2L for some cases of $i$.
\end{abstract}

Key-Words: continuous sampling plan, Markov chain, average total fraction inspected, average total outgoing quality.

Received: February 28, 2020. Revised: July 6, 2020. Accepted: August 1, 2020. Published: August 17, 2020.

\section{Introduction}

An outgrowth of many years of research and consulting in the field of control system are developed to applied to real-world situations. The foundation of statistical tools and techniques of control system have been created by many researchers. Some relevant studies can be found in [1], [2] and [3]. A sampling plan is the one of important parts of control system. Sampling plans can adjust the efficiency of product inspection and reduce the manufacturer's workload whilst at the same time providing a rigorous statistical basis for the sampling and inspection process. The continuous sampling plans (CSPs) are the best sampling plan and used for inspecting each product unit on a production line. The result of the inspection is either conforming or non-confirming for a continuous process. The most advantages of CSPs is that the manufacturer can know the quality of the product after the inspection finished.
The CSPs have been designed and developed continuously from the past to the present. In order to check the quality of the product while it is being produced on the production belt and the characteristics of the product found on the production line. There are 2 types of continuous sampling plans, which are single-level continuous sampling plan and multi-level continuous sampling plan. The first continuous sampling plan, which was created as a single-level continuous sampling plan by Dodge in 1943, is called CSP-1 (Continuous Sampling Plan Type 1) [4]. The procedures of the CSP-1 are as follows. Start inspection with $100 \%$ inspection of units from the flow of production and continue the inspection until $i$ successive conforming units are found, discontinue 100\% inspection and start sampling inspection and inspect only a fraction $f$ of the units, selecting a unit at random from each segment of $1 / f$ items. If a nonconforming unit is found then revert immediately to $100 \%$ inspection. When 
nonconforming units are found, the manufacturer replaces or corrects all the nonconforming units found with conforming units. Therefore, the quality of the products will be better. After that, many researchers have designed and developed many sampling plans, that using CSP-1 as the basis, such as CSP-2, CSP-3, CSP-M, TCSP-1, MCSP-C, MCSP-2-C, CSP-F-L, and G-TF-CSP [5] - [11] and so on.

The CSPs have two product inspection phases: the inspection of every unit or $100 \%$ inspection phase, and the inspection of some units with sampling frequency or sampling inspection phase. While the production process is undergoing product inspection, if the product is found to be defective, that product unit will be withdrawn and replaced with a good product every time. Therefore, at the end of the inspection, the products that have passed inspection have better quality and continuous sampling plans are rectifying inspection plans. In each continuous sampling plan, in addition to designing a product inspection, formulas to measure performance were also created such as average fraction inspected $(A F I)$, average outgoing quality $(A O Q)$, and average outgoing quality limit $(A O Q L)$ of the plan. The value of the performance measure indicates the quality of the product after completion of the inspection or the number of products that are inspected when using this continuous sampling plan to inspect the production process. There are several text books concerning statistical quality control that can be found that offer reviews of CSPs [13] - [17].

The above CSPs are designed for product inspection under the condition that one inspector per production line is used. In 2005, Mayureesawan and Sudasna-Na-Ayudthaya proposed the CSP-1-2L continuous sampling plan to inspect the same type of product on two production lines at the same time but use only one inspector. The limitation of the CSP-1 -2 L is that there is only one inspector, therefore, during the $100 \%$ inspection phase, the inspector is unable to inspect two production lines at the same time. So the inspector has to temporarily stop inspecting one production line. The conditions regarding inspection sequences when inspected with the CSP-1-2L are as follows. First, start with $100 \%$ inspection at production line 1 and temporarily stop inspection at production line 2 and second, in case both production lines have to revert to $100 \%$ inspection at the same time, production line 2 will be reverted to $100 \%$ inspection and inspection of production line 1 will be temporarily stopped. There are four possible forms of the CSP-1-2L. Mayureesawan and Sudasna-Na-Ayudthaya presented the formulas for performance measures, which consists of average total fraction inspected (ATFI), average total outgoing quality $(A T O Q)$ and average total outgoing quality limit (ATOQL) [17].

With regard to the inspection procedure of the CSP-1-2L, the inspection process is complicated and there are many cases of inspection that can occur and this complexity may cause the inspector to confuse the inspection process and cause inspection errors. In addition, defective products may pass without inspection during the pause of the inspection, which causes the quality of the products to be low. Therefore, this paper has improved the inspection procedures of the CSP-1-2L in order to reduce complex inspection procedures. There is no case in which inspection is paused by replacing it with a sampling inspection to reduce the number of defective product units that have passed and expanding the sampling inspection procedures for both production lines when both production lines have a sampling inspection phase at the same time to extended restart $100 \%$ inspection. A new continuous sampling plan designated as the CSP-2L, plans to focus on the production line that is $100 \%$ inspection in progress more than the production line that is sampling inspection in progress and always beginning with the inspection on production line 1 . the CSP-2L always defines that production line 1 is a production line that has a probability of a unit produced by the process being nonconforming $\left(p_{1}\right)$ more than or equal to production line 2 that has a probability of a unit produced by the process being nonconforming of production line $2\left(p_{2}\right)$ and still under conditions that, there is only one inspector to inspect two production lines at the same time and not $100 \%$ inspected at the same time on both production lines.

This paper has the following objectives: to design a new continuous sampling plan for two production lines, namely CSP-2L, to improve the formulas for performance measures, which are average total fraction inspected (ATFI), average total outgoing quality $(A T O Q)$ and average total outgoing quality limit $(A T O Q L)$. This was carried out using a Markov chain, tested the accuracy of formulas to measure the performance of the CSP-2L and compared the $A T O Q$ values from the CSP-2L and the CSP-1-2L plans.

\section{Materials and Methods}

\subsection{The Operating Procedure of the CSP -2L}

In the process of the CSP-2L, the probability of a unit produced by the process being nonconforming of line 1 and line 2 are $p_{1}$ and $p_{2}$, respectively. This 
plan uses five parameters $i_{1}, i_{2}, f_{1}, f_{2}$ and $m$ which are defined by:

$i_{1}=$ the clearance number of line 1
$i_{2}=$ the clearance number of line 2
$f_{1}=$ the sampling fraction of line 1
$f_{2}=$ the sampling fraction of line 2 and
$m=$ the number of units to be found when inspection of line 1 and line 2 are in the phase of sampling inspection at the same time.

The inspection process of the CSP-2L is shown in Figure 1.

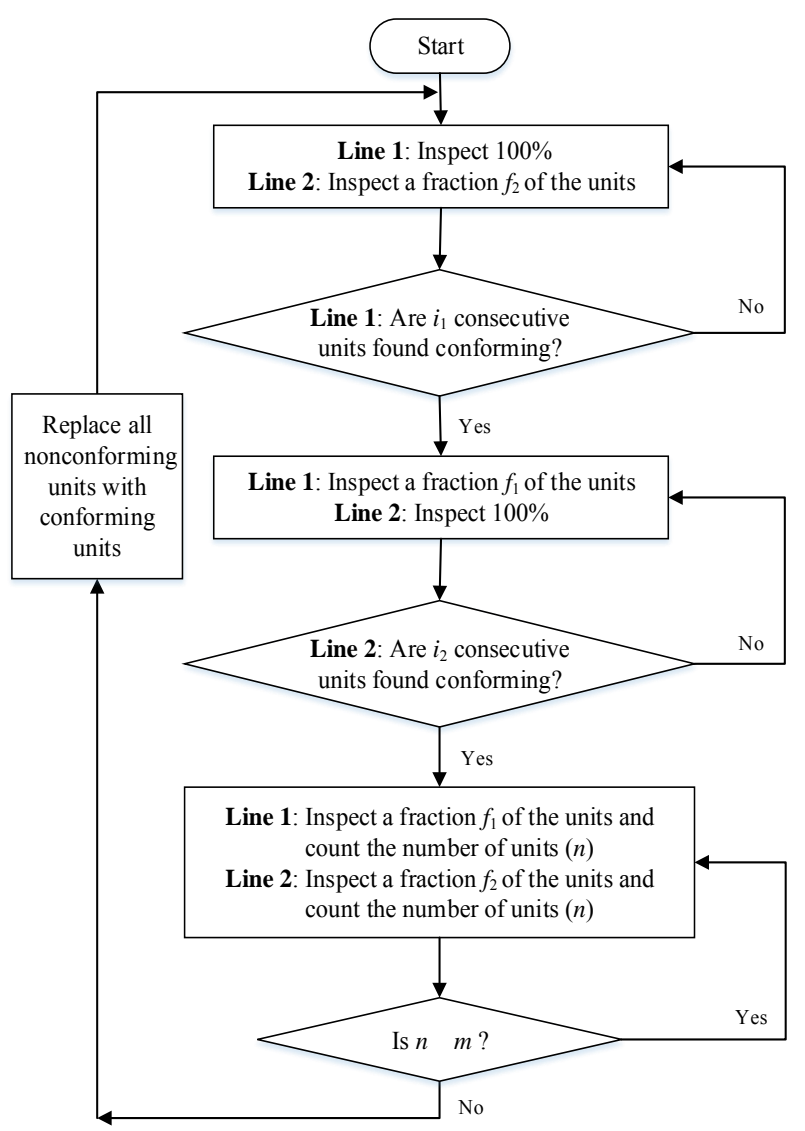

Figure 1. Flow diagram of the inspection process of the CSP-2L.

\subsection{The CSP-2L Procedure as a Markov Chain}

Stephens [18] used a Markov chain model to find certain measures of performance for CSP-1, CSP-2 and CSP-3 plans, assuming that the production process is in statistical control. In this paper the formulas of the CSP-2L procedure as a Markov chain is given. The CSP-2L computes three formulas, the average total fraction inspected (ATFI), the average total outgoing quality (ATOQ) and the average total outgoing quality limit (ATOQL). In addition, the assumption for derivation of these performance measures is both production lines of the CSP-2L are independent.

\section{Definition of symbols}

$S_{n}=$ the $n^{\text {th }}$ state of the process,

$\mathrm{P}\left(S_{n}\right)=$ the steady-state probability for the state $S_{n}$,

$p_{i n}=$ the probability that the process transits from state $S_{i}$ to $S_{n}$ in one step.

The conditions of the steady-state probabilities $\mathrm{P}\left(S_{n}\right)$ are as follows,

$$
\begin{aligned}
& \text { 1. } \mathrm{P}\left(S_{n}\right) \geq 0 \text { for } n=1,2, \ldots, N \text {, } \\
& \text { 2. } \mathrm{P}\left(S_{n}\right)=\sum_{x=1}^{N} \mathrm{P}(S) p_{x n} \\
& \text { for } n=1,2, \ldots, N \text {, } \\
& \text { 3. } \sum_{\text {alln }} \mathrm{P}\left(S_{n}\right)=1 \text {, }
\end{aligned}
$$

where $N$ is finite state [19]

Let $\left[\mathrm{X}_{t}\right](t=1,2, \ldots)$ denote a discrete-parameter of a Markov chain with finite state space $\left(S_{n}\right)$.

The states of the process are defined, in a way similar to that of S. W. Roberts [20] and H. A. Lasater [21], as follows:

At line 1: the states of the process are defined,

$$
\begin{aligned}
S_{j} & =\mathrm{A}_{j-1}\left(j=1,2, \ldots, i_{1}+1\right) \\
& =100 \% \text { inspection is being conducted }
\end{aligned}
$$

and the last $(j-1)$ consecutive units inspected were conforming.

$$
\begin{aligned}
S_{3 k+i_{1}+2} & =f_{1} \mathrm{~N}_{k}\left(k=0,1,2, \ldots, i_{2}\right) \\
& =k \text { consecutive conforming units }
\end{aligned}
$$

found during $100 \%$ inspection of line 2, while inspection of line 1 is in effect at sampling inspection phase and the last unit was not selected for inspection.

$$
\begin{aligned}
S_{3 k+i_{1}+3} & =f_{1} \operatorname{In}_{k}\left(k=0,1,2, \ldots, i_{2}\right) \\
& =k \text { consecutive conforming units }
\end{aligned}
$$

found during $100 \%$ inspection of line 2 , while inspection of line 1 is in effect at sampling inspection phase and the last unit was selected which was found to be conforming.

$$
\begin{aligned}
S_{3 k+i_{1}+4} & =f_{1} \mathrm{Id}_{k}\left(k=0,1,2, \ldots, i_{2}\right) \\
& =k \text { consecutive conforming units }
\end{aligned}
$$

found during $100 \%$ inspection of line 2, while inspection of line 1 is in effect at sampling inspection phase and the last unit was selected which was found to be nonconforming.

$$
\begin{aligned}
S_{3 l+i_{1}+3 i_{2}+2} & =f_{1} \mathrm{~N}_{l-1}^{\prime}(l=1,2, \ldots, m) \\
& =\text { the last unit was not inspected }
\end{aligned}
$$
and the number of inspection units found during inspection is $l-1$, when the inspection of line 1 and line 2 are on the sampling inspection phase at the same time. 


$$
S_{3 l+i_{1}+3 i_{2}+3}=f_{1} \operatorname{In}_{l}^{\prime}(l=1,2, \ldots, m)
$$

$=$ the last unit was found to be conforming and the number of inspection units found during inspection is $l-1$, when the inspection of line 1 and line 2 are on the sampling inspection phase at the same time.

$$
S_{3 l+i_{1}+3 i_{2}+4}=f_{1} \operatorname{Id}_{l}(l=1,2, \ldots, m)
$$$$
=\text { the last unit was found to be }
$$

nonconforming and the number of inspection units found during inspection is $l-1$, when the inspection of line 1 and line 2 are on the sampling inspection phase at the same time.

At line 2: the states of the process are defined,

$$
\begin{aligned}
S_{3 j+i_{1}+3 i_{2}+3 m+5} & =f_{2} \mathrm{~N}_{j}\left(j=0,1,2, \ldots, i_{1}\right) \\
& =j \text { consecutive conforming }
\end{aligned}
$$

units found during 100\% inspection of line 1, while inspection of line 2 is in effect at sampling inspection phase and the last unit was not selected for inspection.

$$
\begin{aligned}
S_{3 j+i_{1}+3 i_{2}+3 m+6} & =f_{2} \operatorname{In}_{j}\left(j=0,1,2, \ldots, i_{1}\right) \\
& =j \text { consecutive conforming }
\end{aligned}
$$

units found during $100 \%$ inspection of line 1 , while inspection of line 2 is in effect at sampling inspection phase and the last unit was selected which was found to be conforming.

$$
\begin{aligned}
S_{3 j+i_{1}+3 i_{2}+3 m+7} & =f_{2} \operatorname{Id}_{j}\left(j=0,1,2, \ldots, i_{1}\right) \\
& =j \text { consecutive conforming }
\end{aligned}
$$

units found during $100 \%$ inspection of line 1, while inspection of line 2 is in effect at sampling inspection phase and the last unit was selected which was found to be nonconforming.

$$
\begin{aligned}
S_{k+4 i_{1}+3 i_{2}+3 m+7} & =\mathrm{B}_{k-1}\left(k=1,2, \ldots, i_{2}+1\right) \\
& =100 \% \text { inspection is being }
\end{aligned}
$$

conducted and the last $(k-1)$ consecutive units inspected were conforming.

$$
\begin{aligned}
S_{3 l+4 i_{1}+4 i_{2}+3 m+6} & =f_{2} \mathrm{~N}_{l-1}^{\prime}(l=1,2, \ldots, m) \\
& =\text { the last unit was not }
\end{aligned}
$$
inspected and the number of inspection units found during inspection is $l-1$, when the inspection of line 1 and line 2 are on the sampling inspection phase at the same time.

$$
\begin{aligned}
S_{3 l+4 i_{1}+4 i_{2}+3 m+7} & =f_{2} \operatorname{In}_{l}^{\prime}(l=1,2, \ldots, m) \\
& =\text { the last unit was found to }
\end{aligned}
$$

be conforming and the number of inspection units found during inspection is $l-1$, when the inspection of line 1 and line 2 are on the sampling inspection phase at the same time.

$$
\begin{aligned}
S_{3 l+4 i_{1}+4 i_{2}+3 m+8} & =f_{2} \operatorname{Id}_{l}^{\prime}(l=1,2, \ldots, m) \\
& =\text { the last unit was found to }
\end{aligned}
$$
be nonconforming and the number of inspection units found during inspection is $l-1$, when the inspection of line 1 and line 2 are on the sampling inspection phase at the same time.

The set of $N$ states (when $N=4 i_{1}+4 i_{2}+6 m+8$ ) defined above completely describe the mutually exclusive phases of inspection for the CSP-2L procedure. A flow chart showing the description of the process by means of states and transitions between different states of the CSP-2L is shown in Figure 2. 


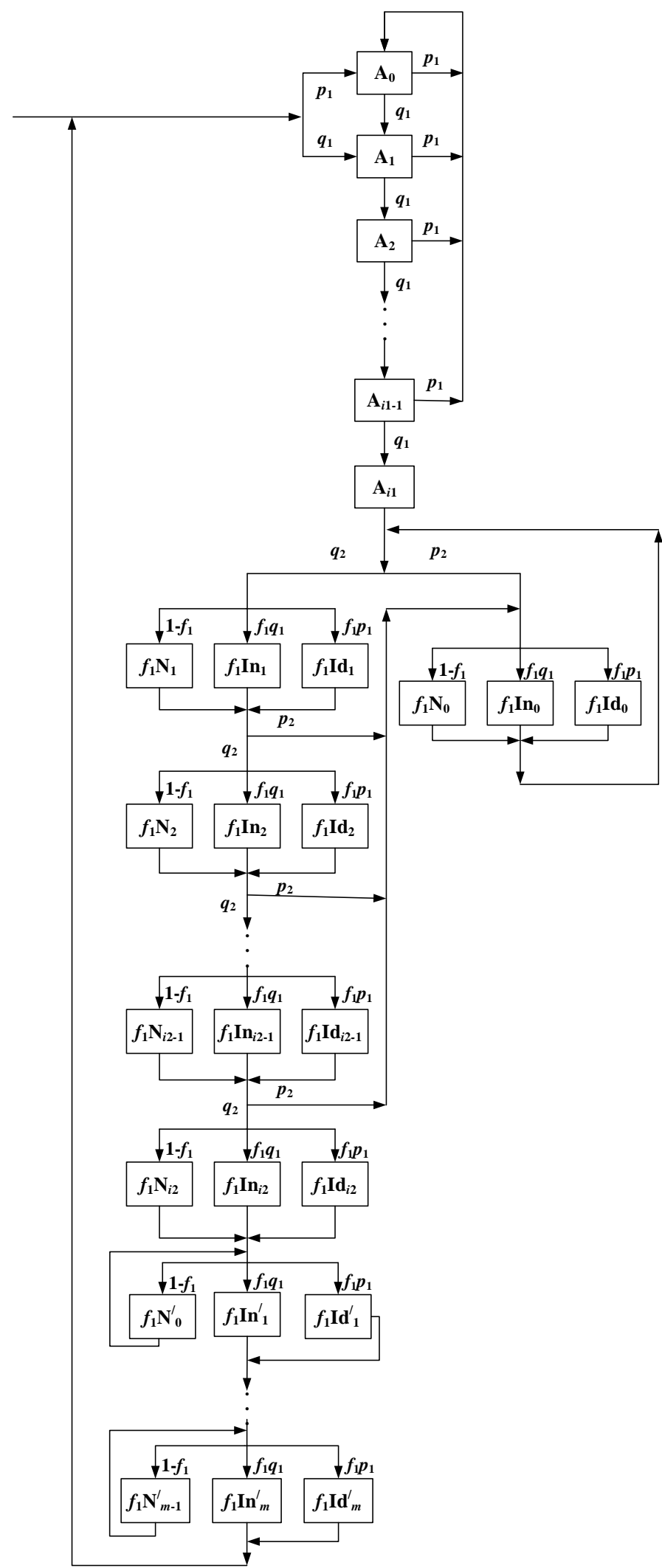

a. Line 1

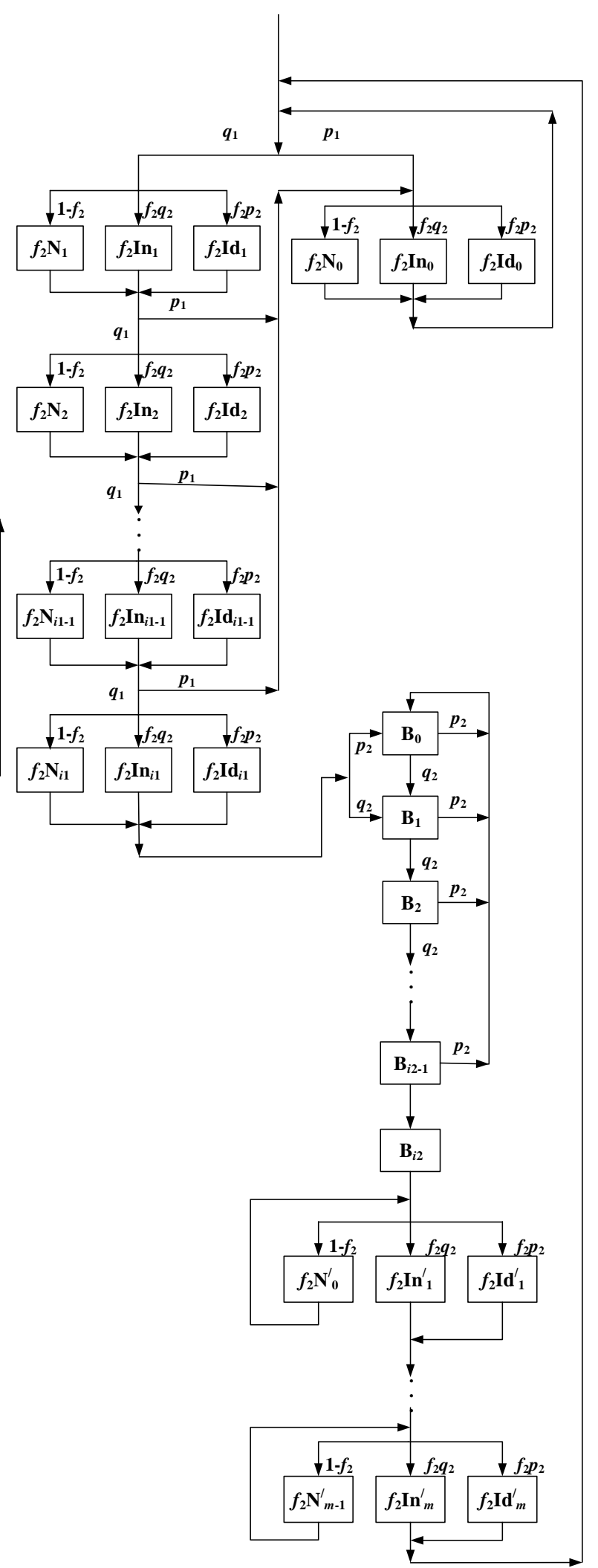

b. Line 2

Figure 2. Flow chart of states and transitions of the CSP-2L. 
From Figure 2 and the definition of a Markov chain, the transition probabilities of a Markov chain and the transition matrix of a Markov chain, that are as follows [19],

Definition 1:

Let $\left\{\mathrm{X}_{0}, \mathrm{X}_{1}, \mathrm{X}_{2}, \ldots\right\}$ be a sequence of discrete random variables. Then $\left\{\mathrm{X}_{0}, \mathrm{X}_{1}, \ldots\right\}$ is a Markov chain if it satisfies the Markov property:

$\mathrm{P}\left(\mathrm{X}_{t+1}=s \mid \mathrm{X}_{t}=\mathrm{s}_{t}, \ldots, \mathrm{X}_{0}=s_{0}\right)=\mathrm{P}\left(\mathrm{X}_{t+1}=s \mid \mathrm{X}_{t}=s_{t}\right)$, for all $t=1,2, \ldots$ and for all states $s_{0}, s_{1}, \ldots, s_{t}, s$.

Table 1. One-step transition probability matrix of line 1 of the CSP-2L.

\begin{tabular}{|c|c|c|c|c|c|c|c|c|c|c|c|c|c|c|c|c|c|c|c|c|c|c|c|c|}
\hline & $A_{0}$ & $\mathbf{A}_{t}$ & $\ldots$ & $\mathbf{A}_{i 1}$ & $f_{1} \mathbf{N}_{0}$ & $f_{1} \mathbf{I} \mathbf{n}_{0}$ & $f_{1} \mathbf{I} \mathbf{d}_{0}$ & $f_{1} \mathbf{N}_{1}$ & $f_{1} \mathbf{I n}_{1}$ & $f_{1} \mathbf{I} \mathbf{d}_{1}$ & $\ldots$ & $f_{1} N_{i 2}$ & $f_{1} \mathbf{I}_{i 2}$ & $f_{1} \mathbf{I} \mathbf{d}_{i 2}$ & $f_{1} \mathbf{N}_{0}^{\prime}$ & $f_{1} \mathbf{I n}_{1}^{\prime}$ & $f_{1} \mathbf{I} d_{1}^{\prime}$ & $f_{1} N_{1}^{\prime}$ & $f_{1} \mathbf{I n}_{2}^{\prime}$ & $f_{1} \mathbf{I} \mathbf{d}_{2}$ & $\ldots$ & $f_{1} \mathbf{N}_{m-1}^{\prime}$ & $f_{1} \mathbf{I n}_{m}^{\prime}$ & $f_{1} \mathbf{I} \mathbf{d}_{m}^{\prime}$ \\
\hline$A_{0}$ & $p_{t}$ & $q_{\mathrm{t}}$ & $\ldots$ & & & & & & & & $\ldots$ & & & & & & & & & & $\ldots$ & & & \\
\hline $\mathbf{A}_{t}$ & $p_{t}$ & & $\ldots$ & & & & & & & & $\ldots$ & & & & & & & & & & $\ldots$ & & & \\
\hline$\ldots$ & $\ldots$ & $\ldots$ & $\ldots$ & $\ldots$ & $\ldots$ & $\ldots$ & $\ldots$ & $\ldots$ & $\ldots$ & $\ldots$ & $\ldots$ & $\ldots$ & $\ldots$ & $\ldots$ & $\ldots$ & $\ldots$ & $\ldots$ & $\ldots$ & $\ldots$ & $\ldots$ & $\ldots$ & $\ldots$ & $\ldots$ & $\ldots$ \\
\hline $\mathbf{A}_{\mathrm{il1}-1}$ & $p_{\mathrm{t}}$ & & $\ldots$ & $q_{\mathrm{t}}$ & & & & & & & $\ldots$ & & & & & & & & & & $\ldots$ & & & \\
\hline $\mathbf{A}_{i 1}$ & & & $\ldots$ & & $p_{2}\left(\mathbf{l}-f_{1}\right)$ & $p_{2} f_{1} q_{1}$ & $p_{2} f_{1} p_{1}$ & $q_{2}\left(\mathbf{l}-f_{1}\right)$ & $q_{2} f_{1} q_{1}$ & $q_{2} f_{1} p_{1}$ & $\ldots$ & & & & & & & & & & $\ldots$ & & & \\
\hline$f_{1} \mathbf{N}_{0}$ & & & $\ldots$ & & $p_{2}\left(\mathbf{l}-f_{1}\right)$ & $p_{2} f_{1} q_{1}$ & $p_{2} f_{1} p_{1}$ & $q_{2}\left(\mathbf{l}-f_{1}\right)$ & $q_{2} f_{1} q_{1}$ & $q_{2} f_{1} p_{1}$ & $\ldots$ & & & & & & & & & & $\ldots$ & & & \\
\hline$f_{1} \mathbf{I n}_{0}$ & & & $\ldots$ & & $p_{2}\left(1-f_{1}\right)$ & $p_{2} f_{1} q_{1}$ & $p_{2} f_{1} p_{1}$ & $q_{2}\left(\mathbf{l}-f_{1}\right)$ & $q_{2} f_{1} q_{1}$ & $q_{2} f_{1} p_{1}$ & $\ldots$ & & & & & & & & & & $\ldots$ & & & \\
\hline$f_{1} \mathbf{I} \mathbf{d}_{0}$ & & & $\ldots$ & & $p_{2}\left(\mathbf{l}-f_{1}\right)$ & $p_{2} f_{1} q_{1}$ & $p_{2} f_{1} p_{1}$ & $q_{2}\left(\mathbf{l}-f_{1}\right)$ & $q_{2} f_{1} q_{1}$ & $q_{2} f_{1} p_{1}$ & $\ldots$ & & & & & & & & & & $\ldots$ & & & \\
\hline$f_{1} \mathbf{N}_{1}$ & & & $\ldots$ & & $p_{2}\left(1-f_{1}\right)$ & $p_{2} f_{1} q_{1}$ & $p_{2} f_{1} p_{1}$ & & & & $\ldots$ & & & & & & & & & & $\ldots$ & & & \\
\hline$f_{1} \mathbf{I n}_{1}$ & & & $\ldots$ & & $p_{2}\left(1-f_{1}\right)$ & $p_{2} f_{1} q_{1}$ & $p_{2} f_{1} p_{1}$ & & & & $\ldots$ & & & & & & & & & & $\ldots$ & & & \\
\hline$f_{1} \mathbf{I} \mathbf{d}_{1}$ & & & $\ldots$ & & $p_{2}\left(1-f_{1}\right)$ & $p_{2} f_{1} q_{1}$ & $p_{2} f_{1} p_{1}$ & & & & $\ldots$ & & & & & & & & & & $\ldots$ & & & \\
\hline$\ldots$ & $\ldots$ & $\ldots$ & $\ldots$ & $\ldots$ & $\ldots$ & $\ldots$ & $\ldots$ & $\ldots$ & $\ldots$ & $\ldots$ & $\ldots$ & $\ldots$ & $\ldots$ & $\ldots$ & $\ldots$ & $\ldots$ & $\ldots$ & $\ldots$ & $\ldots$ & $\ldots$ & $\ldots$ & $\ldots$ & $\ldots$ & $\ldots$ \\
\hline$f_{1} \mathbf{N}_{i 2-1}$ & & & $\ldots$ & & $p_{2}\left(1-f_{1}\right)$ & $p_{2} f_{1} q_{1}$ & $p_{2} f_{1} p_{1}$ & & & & $\ldots$ & $q_{2}\left(\mathbf{l}-f_{1}\right)$ & $q_{2} f_{1} q_{1}$ & $q_{2} f_{1} p_{1}$ & & & & & & & $\ldots$ & & & \\
\hline$f_{1} \mathbf{I n}_{i-1}$ & & & $\ldots$ & & $p_{2}\left(1-f_{1}\right)$ & $p_{2} f_{1} q_{1}$ & $p_{2} f_{1} p_{1}$ & & & & $\ldots$ & $q_{2}\left(1-f_{1}\right)$ & $q_{2} f_{1} q_{1}$ & $q_{2} f_{1} p_{1}$ & & & & & & & $\ldots$ & & & \\
\hline$f_{1} \mathbf{I} \mathbf{d}_{i-1}$ & & & $\ldots$ & & $p_{2}\left(\mathbf{l}-f_{1}\right)$ & $p_{2} f_{1} q_{1}$ & $p_{2} f_{1} p_{1}$ & & & & $\ldots$ & $q_{2}\left(1-f_{1}\right)$ & $q_{2} f_{1} q_{1}$ & $q_{2} f_{1} p_{1}$ & & & & & & & $\ldots$ & & & \\
\hline$f_{1} \mathbf{N}_{i 2}$ & & & $\ldots$ & & & & & & & & $\ldots$ & & & & $1-f_{1}$ & $f_{1} q_{1}$ & $f_{1} p_{1}$ & & & & $\ldots$ & & & \\
\hline$f_{1} \mathbf{I n}_{i 2}$ & & & $\ldots$ & & & & & & & & $\ldots$ & & & & $1-f_{1}$ & $f_{1} q_{1}$ & $f_{1} p_{1}$ & & & & $\ldots$ & & & \\
\hline$f_{1} \mathbf{I} \mathbf{d}_{i 2}$ & & & $\ldots$ & & & & & & & & $\ldots$ & & & & $1-f_{1}$ & $f_{1} q_{1}$ & $f_{1} p_{1}$ & & & & $\ldots$ & & & \\
\hline$f_{1} \mathbf{N}_{0}^{\prime}$ & & & $\ldots$ & & & & & & & & $\ldots$ & & & & $1-f_{1}$ & $f_{1} q_{1}$ & $f_{1} p_{1}$ & & & & $\ldots$ & & & \\
\hline$f_{1} \mathbf{I} \mathbf{n}_{1}^{\prime}$ & & & $\ldots$ & & & & & & & & $\ldots$ & & & & & & & $1-f_{1}$ & $f_{1} q_{1}$ & $f_{1} p_{1}$ & $\ldots$ & & & \\
\hline$f_{1} \mathbf{I} d_{1}$ & & & $\ldots$ & & & & & & & & $\ldots$ & & & & & & & $1-f_{1}$ & $f_{1} q_{1}$ & $f_{1} p_{1}$ & $\ldots$ & & & \\
\hline$f_{1} \mathrm{~N}_{1}^{\prime}$ & & & $\ldots$ & & & & & & & & $\ldots$ & & & & & & & $1-f_{1}$ & $f_{1} q_{1}$ & $f_{1} p_{1}$ & $\ldots$ & & & \\
\hline$f_{1} \mathbf{I} \mathbf{n}_{2}^{\prime}$ & & & $\ldots$ & & & & & & & & $\ldots$ & & & & & & & & & & $\ldots$ & & & \\
\hline$f_{1} \mathbf{I} \mathbf{d}_{2}$ & & & $\ldots$ & & & & & & & & $\ldots$ & & & & & & & & & & $\ldots$ & & & \\
\hline$\ldots$ & $\ldots$ & $\ldots$ & $\ldots$ & $\ldots$ & $\ldots$ & $\ldots$ & $\ldots$ & $\ldots$ & $\ldots$ & $\ldots$ & $\ldots$ & $\ldots$ & $\ldots$ & $\ldots$ & $\ldots$ & $\ldots$ & $\ldots$ & $\ldots$ & $\ldots$ & $\ldots$ & $\ldots$ & $\ldots$ & $\ldots$ & $\ldots$ \\
\hline$f_{1} \mathbf{N}_{m-1}^{\prime}$ & & & $\ldots$ & & & & & & & & $\ldots$ & & & & & & & & & & $\ldots$ & $1-f_{1}$ & $f_{1} q_{1}$ & $f_{1} p_{1}$ \\
\hline$f_{1} \mathbf{I n}_{m}^{\prime}$ & $p_{\mathrm{t}}$ & $q_{\mathrm{i}}$ & $\ldots$ & & & & & & & & $\ldots$ & & & & & & & & & & $\ldots$ & & & \\
\hline$f_{1} \mathbf{I} \mathbf{d}_{m}^{\prime}$ & $p_{\text {s }}$ & $q_{\mathrm{s}}$ & $\ldots$ & & & & & & & & $\ldots$ & & & & & & & & & & $\ldots$ & & & \\
\hline
\end{tabular}

Definition 2:

Let $\left\{\mathrm{X}_{0}, \mathrm{X}_{1}, \mathrm{X}_{2}, \ldots\right\}$ be a Markov chain with state space $S$, where $S$ has size $n$ (possibly infinite). The transition probabilities of the Markov chain are

$$
p_{i j}=\mathrm{P}\left(\mathrm{X}_{t+1}=j \mid \mathrm{X}_{t}=i\right) \text { for } i, j \in S, t=0,1,2, \ldots
$$

\section{Definition 3:}

"The transition matrix of the Markov chain is $P=\left(p_{i j}\right)$ ".

We get the transition matrix of line 1 and the transition matrix of line 2 of the CSP-2L shown in Table 1 and Table 2, respectively. 
Table 2. One-step transition probability matrix of line 2 of the CSP-2L.

\begin{tabular}{|c|c|c|c|c|c|c|c|c|c|c|c|c|c|c|c|c|c|c|c|c|c|c|c|c|}
\hline & $f_{2} \mathbf{N}_{0}$ & $f_{2} \mathbf{I n}_{0}$ & $f_{2} \mathbf{I} \mathbf{d}_{0}$ & $f_{2} \mathbf{N}_{1}$ & $f_{2} \mathbf{I}_{1}$ & $f_{2} \mathbf{I} \mathbf{d}_{1}$ & $\ldots$ & $f_{2} \mathbf{N}_{\text {il }}$ & $f_{2} \mathbf{I}_{i 1}$ & $f_{2} \mathbf{I} \mathbf{d}_{i 1}$ & $\mathbf{B}_{0}$ & $\mathbf{B}_{t_{t}}$ & $\ldots$ & $\mathbf{B}_{i 2}$ & $f_{2} \mathbf{N}_{0}^{\prime}$ & $f_{2} \mathbf{I n}_{1}^{\prime}$ & $f_{2} \mathbf{I} \mathbf{d}_{1}^{\prime}$ & $f_{2} \mathrm{~N}_{1}^{\prime}$ & $f_{2} \mathbf{I} \mathbf{n}_{2}^{\prime}$ & $f_{2} \mathbf{I} \mathbf{d}_{2}^{\prime \prime 2}$ & $\ldots$ & $f_{2} \mathbf{N}_{m-1}^{\prime}$ & $f_{2} \mathbf{I n}_{m}^{\prime}$ & $f_{2} \mathbf{I d}_{m}^{\prime}$ \\
\hline$f_{2} \mathbf{N}_{0}$ & $p_{1}\left(1-f_{2}\right)$ & $p_{1} f_{2} q_{2}$ & $p_{1} f_{2} p_{2}$ & $q_{1}\left(1-f_{2}\right)$ & $q_{1} f_{2} q_{2}$ & $q_{1} f_{2} p_{2}$ & $\ldots$ & & & & & & $\ldots$ & & & & & & & & & & & \\
\hline$f_{2} \mathbf{I n}_{0}$ & $p_{1}\left(1-f_{2}\right)$ & $p_{1} f_{2} q_{2}$ & $p_{1} f_{2} p_{2}$ & $q_{1}\left(1-f_{2}\right)$ & $q_{1} f_{2} q_{2}$ & $q_{1} f_{2} p_{2}$ & $\ldots$ & & & & & & $\ldots$ & & & & & & & & $\ldots$ & & & \\
\hline$f_{2} \mathbf{I d}_{0}$ & $p_{1}\left(1-f_{2}\right)$ & $p_{1} f_{2} q_{2}$ & $p_{1} f_{2} p_{2}$ & $q_{1}\left(1-f_{2}\right)$ & $q_{1} f_{2} q_{2}$ & $q f_{2} p_{2}$ & $\ldots$ & & & & & & $\ldots$ & & & & & & & & $\ldots$ & & & \\
\hline$f_{2} \mathbf{N}_{1}$ & $p_{1}\left(1-f_{2}\right)$ & $p_{1} f_{2} q_{2}$ & $p_{1} f_{2} p_{2}$ & & & & $\ldots$ & & & & & & $\ldots$ & & & & & & & & $\ldots$ & & & \\
\hline$f_{2} \mathbf{I n}_{1}$ & $p_{1}\left(1-f_{2}\right)$ & $p_{1} f_{2} q_{2}$ & $p_{1} f_{2} p_{2}$ & & & & $\ldots$ & & & & & & $\ldots$ & & & & & & & & $\ldots$ & & & \\
\hline$f_{2} \mathbf{I} \mathbf{d}_{1}$ & $p_{1}\left(1-f_{2}\right)$ & $p_{1} f_{2} q_{2}$ & $p_{1} f_{2} p_{2}$ & & & & $\ldots$ & & & & & & $\ldots$ & & & & & & & & $\ldots$ & & & \\
\hline$\ldots$ & $\ldots$ & $\ldots$ & $\ldots$ & $\ldots$ & $\ldots$ & $\ldots$ & $\ldots$ & $\ldots$ & $\ldots$ & $\ldots$ & $\ldots$ & $\ldots$ & $\ldots$ & $\ldots$ & $\ldots$ & $\ldots$ & $\ldots$ & $\ldots$ & $\ldots$ & $\ldots$ & $\ldots$ & $\ldots$ & $\ldots$ & $\ldots$ \\
\hline$f_{2} \mathbf{N}_{\mathrm{i}-1}$ & $p_{1}\left(1-f_{2}\right)$ & $p_{1} f_{2} q_{2}$ & $p_{1} f_{2} p_{2}$ & & & & $\ldots$ & $q_{1}\left(1-f_{2}\right)$ & $q_{1} f_{2} q_{2}$ & $q_{1} f_{2} p_{2}$ & & & $\ldots$ & & & & & & & & $\ldots$ & & & \\
\hline$f_{2} \mathbf{I}_{i-1}$ & $p_{1}\left(1-f_{2}\right)$ & $p_{1} f_{2} q_{2}$ & $p_{1} f_{2} p_{2}$ & & & & $\ldots$ & $q_{1}\left(1-f_{2}\right)$ & $q_{1} f_{2} q_{2}$ & $q_{1} f_{2} p_{2}$ & & & $\ldots$ & & & & & & & & $\ldots$ & & & \\
\hline$f_{2} \mathbf{I d}_{\mathrm{il}-1}$ & $p_{1}\left(1-f_{2}\right)$ & $p_{1} f_{2} q_{2}$ & $p_{1} f_{2} p_{2}$ & & & & $\ldots$ & $q_{1}\left(1-f_{2}\right)$ & $q_{1} f_{2} q_{2}$ & $q_{1} f_{2} p_{2}$ & & & $\ldots$ & & & & & & & & $\ldots$ & & & \\
\hline$f_{2} \mathbf{N}_{i}$ & & & & & & & $\ldots$ & & & & $p_{2}$ & $q_{2}$ & $\ldots$ & & & & & & & & $\ldots$ & & & \\
\hline$f_{2} \mathbf{I n}_{i 1}$ & & & & & & & $\ldots$ & & & & $p_{2}$ & $q_{2}$ & $\ldots$ & & & & & & & & $\ldots$ & & & \\
\hline$f_{2} \mathbf{I d}_{i 1}$ & & & & & & & $\ldots$ & & & & $p_{2}$ & $q_{2}$ & $\ldots$ & & & & & & & & $\ldots$ & & & \\
\hline $\mathrm{B}_{8}$ & & & & & & & $\ldots$ & & & & $p_{2}$ & $q_{2}$ & $\ldots$ & & & & & & & & $\ldots$ & & & \\
\hline $\mathbf{B}_{\mathrm{s}}$ & & & & & & & $\ldots$ & & & & $p_{2}$ & & $\ldots$ & & & & & & & & $\ldots$ & & & \\
\hline$\ldots$ & $\ldots$ & $\ldots$ & $\ldots$ & $\ldots$ & $\ldots$ & $\ldots$ & $\ldots$ & $\ldots$ & $\ldots$ & $\ldots$ & $\ldots$ & $\ldots$ & $\ldots$ & $\ldots$ & $\ldots$ & $\ldots$ & $\ldots$ & $\ldots$ & $\ldots$ & $\ldots$ & $\ldots$ & $\ldots$ & $\ldots$ & $\ldots$ \\
\hline $\mathbf{B}_{i 2-1}$ & & & & & & & $\ldots$ & & & & $p_{2}$ & & & $q_{2}$ & & & & & & & & & & \\
\hline $\mathbf{B}_{i 2}$ & & & & & & & 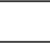 & & & & & & $\ldots$ & & $1-f_{2}$ & $f_{2} q_{2}$ & $f_{2} p_{2}$ & & & & $\ldots$ & & & \\
\hline$f_{2} \mathrm{~N}_{6}^{\prime}$ & & & & & & & $\ldots$ & & & & & & $\ldots$ & & $1-f_{2}$ & $f_{2} q_{2}$ & $f_{2} p_{2}$ & & & & $\ldots$ & & & \\
\hline$f_{2} \mathbf{I n}_{1}^{\prime}$ & & & & & & & $\ldots$ & & & & & & $\ldots$ & & & & & $1-f_{2}$ & $f_{2} q_{2}$ & $f_{2} p_{2}$ & $\ldots$ & & & \\
\hline$f_{2} \mathbf{I d}_{1}^{\prime}$ & & & & & & & $\ldots$ & & & & & & $\ldots$ & & & & & $1-f_{2}$ & $f_{2} q_{2}$ & $f_{2} p_{2}$ & $\ldots$ & & & \\
\hline$f_{2} \mathrm{~N}_{1}^{\prime}$ & & & & & & & $\ldots$ & & & & & & $\ldots$ & & & & & $1-f_{2}$ & $f_{2} q_{2}$ & $f_{2} p_{2}$ & $\ldots$ & & & \\
\hline$f_{2} \mathbf{I n}_{2}^{\prime}$ & & & & & & & $\ldots$ & & & & & & $\ldots$ & & & & & & & & $\ldots$ & & & \\
\hline$f_{2} \mathbf{I d}_{2}^{\prime}$ & & & & & & & $\ldots$ & & & & & & $\ldots$ & & & & & & & & $\ldots$ & & & \\
\hline$\ldots$ & $\ldots$ & $\ldots$ & $\ldots$ & $\ldots$ & $\ldots$ & $\ldots$ & $\ldots$ & $\ldots$ & $\ldots$ & $\ldots$ & $\ldots$ & $\ldots$ & $\ldots$ & $\ldots$ & $\ldots$ & $\ldots$ & $\ldots$ & $\ldots$ & $\ldots$ & $\ldots$ & $\ldots$ & $\ldots$ & $\ldots$ & $\ldots$ \\
\hline$f_{2} \mathbf{N}_{m-1}^{\prime}$ & & & & & & & $\ldots$ & & & & & & $\ldots$ & & & & & & & & $\ldots$ & $1-f_{2}$ & $f_{2} q_{2}$ & $f_{2} p_{2}$ \\
\hline$f_{2} \mathbf{I n}_{m}^{\prime}$ & $p_{1}\left(1-f_{2}\right)$ & $p_{1} f_{2} q_{2}$ & $p_{1} f_{2} p_{2}$ & $q_{1}\left(1-f_{2}\right)$ & $q_{1} f_{2} q_{2}$ & $q_{1} f_{2} p_{2}$ & $\ldots$ & & & & & & $\ldots$ & & & & & & & & $\ldots$ & & & \\
\hline$f_{2} \mathbf{I} \mathbf{d}_{m}^{\prime}$ & $p_{1}\left(1-f_{2}\right)$ & $p_{1} f_{2} q_{2}$ & $p_{1} f_{2} p_{2}$ & $q_{1}\left(1-f_{2}\right)$ & $q_{1} f_{2} q_{2}$ & $q_{1} f_{2} p_{2}$ & $\ldots$ & & & & & & $\ldots$ & & & & & & & & $\ldots$ & & & \\
\hline
\end{tabular}




\subsection{Test of the Accuracy of Performance} Measures for the CSP-2L

For testing the accuracy of the formulas to measure the performance that are defined for the CSP-2L, the results from the formulas were compared with the values obtained from extensive simulations and the simulation was repeated 500 times which more than [17] who repeated 60 times.

Two different lines were examined for the probability of a unit produced by the process being nonconforming of line 1 and line 2 are $p_{1}$ and $p_{2}$, respectively. When $p_{1}=p_{2}=p=0.005,0.015$ and 0.035 . For each $p$, values of $i_{1}=i_{2}=10,20,30,40$ and 50 , values of $f_{1}=f_{2}=1 / 2$ and $1 / 3$, and values of $m=i_{1}$ and $2 i_{1}$.

The average total fraction inspected $(A T F I)$ and the average total outgoing quality ( $A T O Q$ ) were calculated, and then compared the values ATFI and $A T O Q$ from the simulations with the values of ATFI and $A T O Q$ computed from the formulas.

The percentage difference of the ATFI values (\%dif_ATFI) is the ratio of the difference between the $A \bar{T} F I$ values from formula and simulations over the $A T F I$ values from simulations shown in equation (1) and the percentage difference of the $A T O Q$ values (\%dif_ATOQ) is the ratio of the difference between the $A T O Q$ values from formula and simulations over the $A T O Q$ values from simulations shown in equation (2). The ATFI and ATOQ formulas are accepted as the accurate formulas if $\%$ dif_ATFI and \%dif_ATOQ are less than or equal to $2 \%[11]$.

$$
\begin{gathered}
\% \text { dif_ATFI }=\left|\frac{A T F I \_\mathrm{F}-A T F I \_\mathrm{S}}{A T F I \_\mathrm{S}}\right| \times 100 \\
\% \operatorname{dif} \_A T O Q=\left|\frac{A T O Q \_\mathrm{F}-A T O Q \_\mathrm{S}}{A T O Q \_\mathrm{S}}\right| \times 100
\end{gathered}
$$

Where

ATFI $\mathrm{F}$ was the ATFI value from the formula of the CSP-2L,

ATFI S was the ATFI value from the simulations of the CSP-2L,

$A T O Q \_\mathrm{F}$ was the $A T O Q$ value from the formula of the CSP-2L,

$A T O Q \_\mathrm{S}$ was the $A T O Q$ value from the simulations of the CSP-2L.

\section{Results}

\subsection{The Formulas to Measure the Performance of the CSP-2L}

Let $p_{1}$ and $p_{2}$ be the probability of a unit produced by the process being nonconforming of line 1 and line 2 , when $q_{1}=1-p_{1}$ and $q_{2}=1-p_{2}$. The following formulas to measure the performance may be obtained:

The average number of units inspected under the $100 \%$ inspection of line $1, u_{1}$ :

$$
u_{1}=\frac{1-q_{1}^{i_{1}}}{p_{1} q_{1}^{i_{1}}}
$$

The average number of units inspected under the $100 \%$ inspection of line $2, u_{2}$ :

$$
u_{2}=\frac{1-q_{2}^{i_{2}}}{p_{2} q_{2}^{i_{2}}} .
$$

The average number of units passed under the sampling inspection of line $1, v_{1}$ :

$$
v_{1}=\frac{f_{1}\left(1-q_{2}^{i_{2}}\right)+m\left(q_{2}^{i_{2}}-q_{2}^{i_{2}+1}\right)}{f_{1} p_{2} q_{2}^{i_{2}}} .
$$

The average number of units passed under the sampling inspection of line 2, $v_{2}$ :

$$
v_{2}=\frac{f_{2}\left(1-q_{1}^{i_{1}}\right)+m\left(q_{1}^{i_{1}}-q_{1}^{i_{i}+1}\right)}{f_{2} p_{1} q_{1}^{i_{1}}} .
$$

The average total fraction inspected, ATFI:

$$
A T F I=\frac{u_{1}+f_{1} v_{1}+u_{2}+f_{2} v_{2}}{u_{1}+v_{1}+u_{2}+v_{2}} .
$$

The average total outgoing quality, $A T O Q$ :

$$
A T O Q=\frac{p_{1}+p_{2}}{2}[1-A T F I] .
$$

The average total outgoing quality limit, ATOQL:

$$
A T O Q L=\max _{\text {all } p_{1}, p_{2}} A T O Q .
$$

Details of the steps for finding the performance measure formulas are presented in the Appendix.

\subsection{The Accuracy of Formulas to Measure the Performance for the CSP-2L \\ 3.2.1 The ATFI Formula}

The ATFI values from the formula (ATFI_F), the ATFI values from the simulations (ATFI_S) and the percentage difference of the ATFI values (\%dif_ATFI) for each set of $p_{1}, p_{2}, i_{1}, i_{2}, f_{1}$ and $f_{2}$ values are shown in Table 3 and Table 4 for $m=i_{1}$ and $2 i_{1}$ values, respectively. It was also found that, at all levels of $p_{1}$ and $p_{2}$, \%dif ATFI was less than $2 \%$ for all sets of $i_{1}, i_{2}, \overline{f_{1}}, f_{2}$ and $m$ values. Therefore, the simulations signified that the ATFI formula is accurate.

\subsubsection{The $A T O Q$ and the $A T O Q L$ Formulas}

In Table 5 and Table 6 , the $A T O Q$ values from the formula ( $\left.A T O Q_{-} \mathrm{F}\right)$, the $A T O Q$ values from the simulations (ATOQ_S) and the percentage 
difference of the $A T O Q$ values (\%dif_ATOQ) for each set of $p_{1}, p_{2}, i_{1}, i_{2}, f_{1}$ and $f_{2}$ values are shown for $m=i_{1}$ and $2 i_{1}$ values, respectively. It was found that, at all levels of $p_{1}$ and $p_{2}$, the \%dif_ATOQ was less than $2 \%$ for all sets of $i_{1}, i_{2}, f_{1}, f_{2}$ and $m$ values. So the simulations implied that the $A T O Q$ formula is accurate. In addition, from the relationship between the $A T O Q L$ and the $A T O Q$, the ATOQL formula is also accurate.

Table 3. The ATFI_F, ATFI_S and \%dif_ATFI values of the CSP-2L $\mathrm{L}^{1 / 3}$ when $m=i_{1}$

\begin{tabular}{|c|c|c|c|c|c|c|c|}
\hline \multirow{2}{*}{$p_{1}=p_{2}$} & \multirow{2}{*}{$i_{1}=i_{2}$} & \multicolumn{3}{|c|}{$f_{1}=f_{2}=1 / 2$} & \multicolumn{3}{|c|}{$f_{1}=f_{2}=$} \\
\hline & & ATFI_F & ATFI_S & \%dif_ATFI & ATFI_F & ATFI_S & $\% \operatorname{dif} A T F I$ \\
\hline \multirow{5}{*}{0.005} & 10 & 0.62673 & 0.62651 & 0.04 & 0.46889 & 0.46219 & 1.45 \\
\hline & 20 & 0.62831 & 0.62849 & 0.03 & 0.47093 & 0.46488 & 1.30 \\
\hline & 30 & 0.62991 & 0.62970 & 0.03 & 0.47300 & 0.47282 & 0.04 \\
\hline & 40 & 0.63152 & 0.63177 & 0.04 & 0.47510 & 0.47396 & 0.24 \\
\hline & 50 & 0.63314 & 0.63397 & 0.13 & 0.47722 & 0.47586 & 0.29 \\
\hline \multirow{5}{*}{0.015} & 10 & 0.63025 & 0.63025 & 0.00 & 0.47345 & 0.46709 & 1.36 \\
\hline & 20 & 0.63513 & 0.63490 & 0.04 & 0.47985 & 0.47353 & 1.33 \\
\hline & 30 & 0.64010 & 0.63946 & 0.10 & 0.48647 & 0.48585 & 0.13 \\
\hline & 40 & 0.64514 & 0.64367 & 0.23 & 0.49330 & 0.49012 & 0.65 \\
\hline & 50 & 0.65022 & 0.64859 & 0.25 & 0.50030 & 0.49605 & 0.86 \\
\hline \multirow{5}{*}{0.035} & 10 & 0.63753 & 0.63783 & 0.05 & 0.48304 & 0.47748 & 1.1 \\
\hline & 20 & 0.64938 & 0.64680 & 0.40 & 0.49914 & 0.49034 & 1.79 \\
\hline & 30 & 0.66138 & 0.65707 & 0.65 & 0.51610 & 0.51079 & 1.04 \\
\hline & 40 & 0.67322 & 0.66682 & 0.95 & 0.53354 & 0.52399 & 1.82 \\
\hline & 50 & 0.68458 & 0.68071 & 0.57 & 0.55097 & 0.54473 & 1.15 \\
\hline
\end{tabular}

Table 4. The ATFI_F, ATFI_S and \%dif ATFI values of the CSP-2L $\mathrm{L}^{1 / 3}$ when $m=2 i_{1}$

\begin{tabular}{|c|c|c|c|c|c|c|c|}
\hline \multirow{2}{*}{$p_{1}=p_{2}$} & \multirow{2}{*}{$i_{1}=i_{2}$} & \multicolumn{3}{|c|}{$f_{1}=f_{2}=1 / 2$} & \multicolumn{3}{|c|}{$f_{1}=f_{2}=$} \\
\hline & & ATFI_F & ATFI_S & \%dif_ATFI & ATFI_F & ATFI_S & \%dif_ATFI \\
\hline \multirow{5}{*}{0.005} & 10 & 0.58488 & 0.58479 & 0.02 & 0.41841 & 0.41426 & 1.00 \\
\hline & 20 & 0.58631 & 0.58658 & 0.05 & 0.42003 & 0.41635 & 0.88 \\
\hline & 30 & 0.58776 & 0.58766 & 0.02 & 0.42168 & 0.42160 & 0.02 \\
\hline & 40 & 0.58923 & 0.58955 & 0.05 & 0.42336 & 0.42278 & 0.14 \\
\hline & 50 & 0.59073 & 0.59159 & 0.15 & 0.42508 & 0.42448 & 0.14 \\
\hline \multirow{5}{*}{0.015} & 10 & 0.58807 & 0.58831 & 0.04 & 0.42203 & 0.41822 & 0.91 \\
\hline & 20 & 0.59259 & 0.59264 & 0.01 & 0.42723 & 0.42336 & 0.91 \\
\hline & 30 & 0.59732 & 0.59697 & 0.06 & 0.43274 & 0.43242 & 0.07 \\
\hline & 40 & 0.60225 & 0.60109 & 0.19 & 0.43857 & 0.43636 & 0.51 \\
\hline & 50 & 0.60736 & 0.60604 & 0.22 & 0.44471 & 0.44171 & 0.68 \\
\hline \multirow{5}{*}{0.035} & 10 & 0.59486 & 0.59575 & 0.15 & 0.42986 & 0.42691 & 0.69 \\
\hline & 20 & 0.60651 & 0.60463 & 0.31 & 0.44368 & 0.43779 & 1.35 \\
\hline & 30 & 0.61914 & 0.61543 & 0.60 & 0.45924 & 0.45500 & 0.93 \\
\hline & 40 & 0.63252 & 0.62627 & 1.00 & 0.47640 & 0.46806 & 1.78 \\
\hline & 50 & 0.64630 & 0.64291 & 0.53 & 0.49489 & 0.48988 & 1.02 \\
\hline
\end{tabular}

\subsection{The Comparison of the $A T O Q$ values between the CSP-1-2L and the CSP-2L plans.}

To say which production line is better quality, it can be considered from the $A T O Q$ value. If the $A T O Q$ value of any plan is lower, that plan will have better quality production lines.

Therefore, the values of $A T O Q$ for the CSP- $2 \mathrm{~L}$ were compared with the values of $A T O Q$ for the
CSP-1-2L. When defined, the values of the parameters are $p_{1}=p_{2}=p=0.008,0.01$ and 0.03 . For each $p$, values of $i_{1}=i_{2}=i=10,20,30,40$ and 50 , values of $f_{1}=f_{2}=f=1 / 2$ and $1 / 3$, and the value of $m=i$. The ATOQ values of the CSP-2L and the CSP-1-2L plans are shown in Figure 3 to Figure 5. 
Table 5. The $A T O Q \_$F, $A T O Q \_$S and $\%$ dif_ $A T O Q$ values of the CSP- $2 L^{3}$ when $m=i_{1}$

\begin{tabular}{|c|c|c|c|c|c|c|c|}
\hline \multirow{2}{*}{$p_{1}=p_{2}$} & \multirow{2}{*}{$i_{1}=i_{2}$} & \multicolumn{3}{|c|}{$f_{1}=f_{2}=1 / 2$} & \multicolumn{3}{|c|}{$f_{1}=f_{2}=$} \\
\hline & & $A T O Q \_\mathrm{F}$ & $A T O Q \_\mathrm{S}$ & \%dif_ATOQ & $A T O Q \_\mathrm{F}$ & $A T O Q \_\mathrm{S}$ & \%dif_ATOQ \\
\hline \multirow{5}{*}{0.005} & 10 & 0.00187 & 0.00185 & 0.85 & 0.00266 & 0.00263 & 0.89 \\
\hline & 20 & 0.00186 & 0.00183 & 1.33 & 0.00265 & 0.00266 & 0.49 \\
\hline & 30 & 0.00185 & 0.00183 & 1.17 & 0.00263 & 0.00267 & 1.42 \\
\hline & 40 & 0.00184 & 0.00186 & 0.74 & 0.00262 & 0.00259 & 1.45 \\
\hline & 50 & 0.00183 & 0.00181 & 1.20 & 0.00261 & 0.00257 & 1.64 \\
\hline \multirow{5}{*}{0.015} & 10 & 0.00555 & 0.00564 & 1.61 & 0.00790 & 0.00794 & 0.57 \\
\hline & 20 & 0.00547 & 0.00537 & 1.85 & 0.00780 & 0.00767 & 1.71 \\
\hline & 30 & 0.00540 & 0.00535 & 0.91 & 0.00770 & 0.00760 & 1.41 \\
\hline & 40 & 0.00532 & 0.00525 & 1.37 & 0.00760 & 0.00746 & 1.84 \\
\hline & 50 & 0.00525 & 0.00515 & 1.80 & 0.00750 & 0.00744 & 0.78 \\
\hline \multirow{5}{*}{0.035} & 10 & 0.01269 & 0.01263 & 0.41 & 0.01809 & 0.01785 & 1.39 \\
\hline & 20 & 0.01227 & 0.01213 & 1.19 & 0.01753 & 0.01732 & 1.20 \\
\hline & 30 & 0.01185 & 0.01172 & 1.19 & 0.01694 & 0.01708 & 0.84 \\
\hline & 40 & 0.01144 & 0.01146 & 0.22 & 0.01633 & 0.01612 & 1.29 \\
\hline & 50 & 0.01104 & 0.01093 & 1.01 & 0.01572 & 0.01550 & 1.37 \\
\hline
\end{tabular}

Table 6. The $A T O Q \_$F, $A T O Q \_\mathrm{S}$ and $\%$ dif $\_A T O Q$ values of the CSP- $2^{1 / 2} \mathrm{~L}$ when $m=2 i_{1}$

\begin{tabular}{|c|c|c|c|c|c|c|c|}
\hline \multirow{2}{*}{$p_{1}=p_{2}$} & \multirow{2}{*}{$i_{1}=i_{2}$} & \multicolumn{3}{|c|}{$f_{1}=f_{2}=1 / 2$} & \multicolumn{3}{|c|}{$f_{1}=f_{2}=$} \\
\hline & & $A T O Q \_\mathrm{F}$ & $A T O Q \_\mathrm{S}$ & $\%$ dif_ATOQ & $A T O Q \_\mathrm{F}$ & $A T O Q \_\mathrm{S}$ & \%dif_ATOQ \\
\hline \multirow{5}{*}{0.005} & 10 & 0.00208 & 0.00204 & 1.57 & 0.00291 & 0.00288 & 1.02 \\
\hline & 20 & 0.00207 & 0.00204 & 1.42 & 0.00290 & 0.00290 & 0.11 \\
\hline & 30 & 0.00206 & 0.00208 & 0.90 & 0.00289 & 0.00289 & 0.17 \\
\hline & 40 & 0.00205 & 0.00204 & 0.84 & 0.00288 & 0.00284 & 1.45 \\
\hline & 50 & 0.00205 & 0.00202 & 1.37 & 0.00287 & 0.00286 & 0.51 \\
\hline \multirow{5}{*}{0.015} & 10 & 0.00618 & 0.00612 & 0.99 & 0.00867 & 0.00856 & 1.28 \\
\hline & 20 & 0.00611 & 0.00601 & 1.63 & 0.00859 & 0.00852 & 0.80 \\
\hline & 30 & 0.00604 & 0.00597 & 1.22 & 0.00851 & 0.00842 & 1.04 \\
\hline & 40 & 0.00597 & 0.00590 & 1.19 & 0.00842 & 0.00833 & 1.07 \\
\hline & 50 & 0.00589 & 0.00583 & 1.00 & 0.00833 & 0.00825 & 0.98 \\
\hline \multirow{5}{*}{0.035} & 10 & 0.01418 & 0.01397 & 1.50 & 0.01995 & 0.01964 & 1.59 \\
\hline & 20 & 0.01377 & 0.01356 & 1.58 & 0.01947 & 0.01920 & 1.42 \\
\hline & 30 & 0.01333 & 0.01312 & 1.56 & 0.01893 & 0.01866 & 1.41 \\
\hline & 40 & 0.01286 & 0.01293 & 0.53 & 0.01833 & 0.01803 & 1.66 \\
\hline & 50 & 0.01238 & 0.01241 & 0.28 & 0.01768 & 0.01740 & 1.61 \\
\hline
\end{tabular}

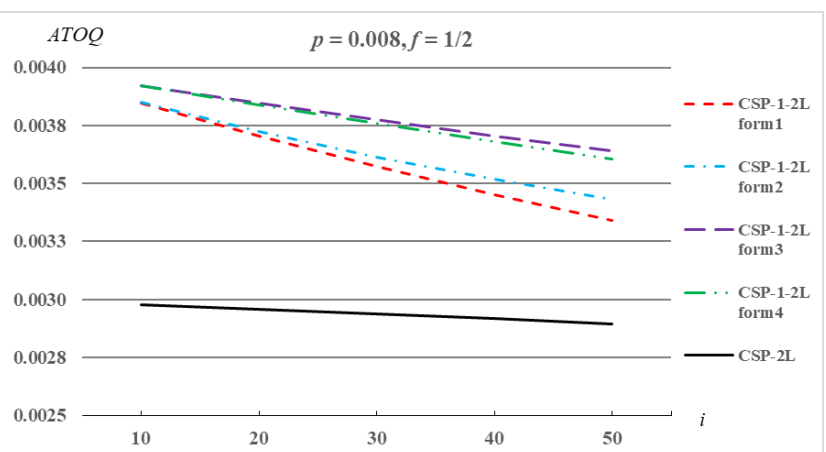

(c)

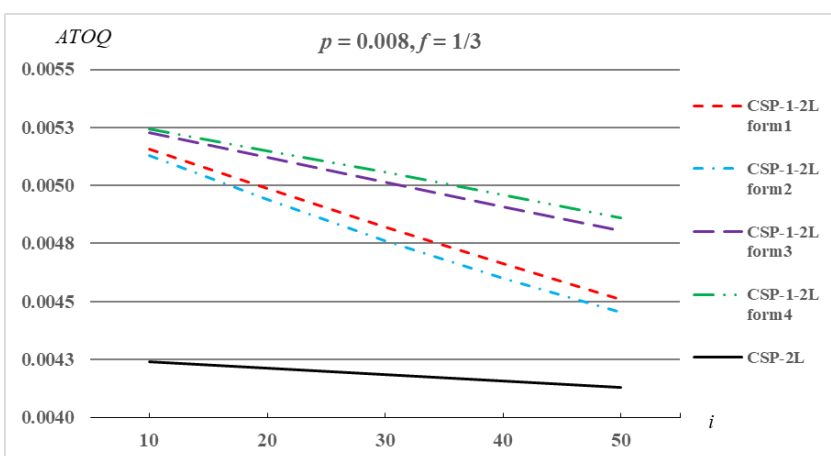

(d)

Figure 3. The $A T O Q$ values of the CSP-1-2L and the CSP-2L plans when $p=0.008$. 


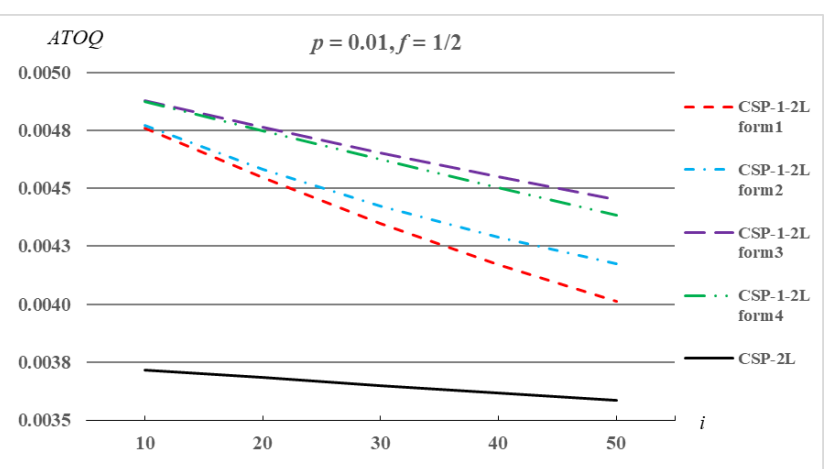

(e)

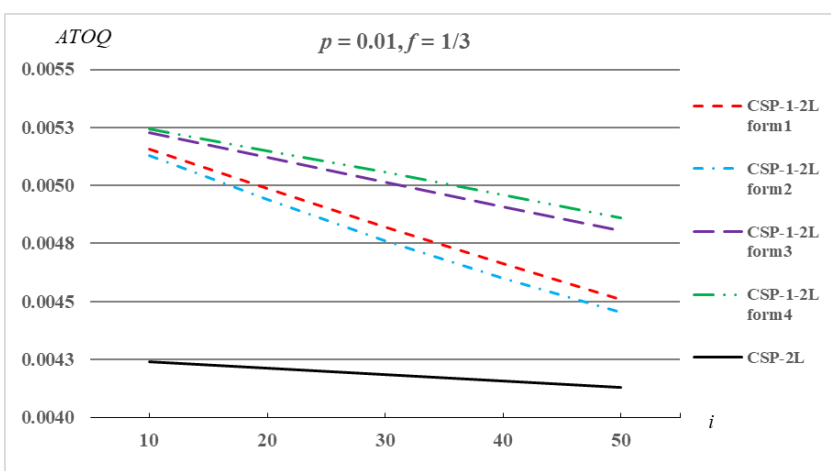

(f)

Figure 4. The $A T O Q$ values of the CSP-1-2L and the CSP-2L plans when $p=0.01$.

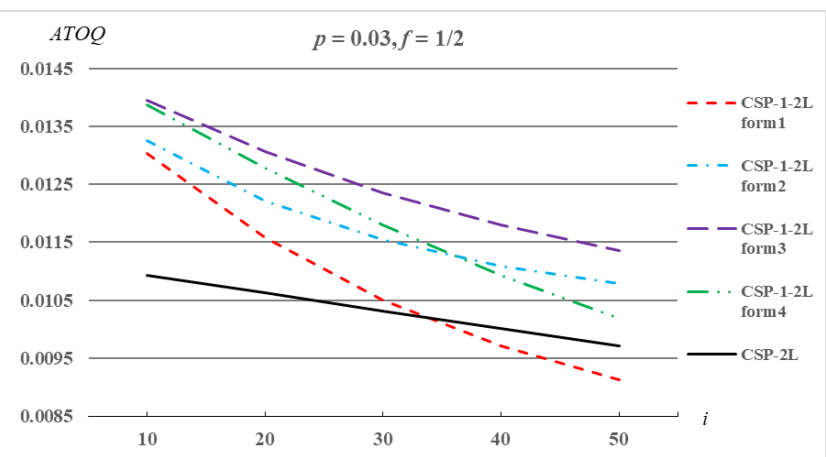

(g)

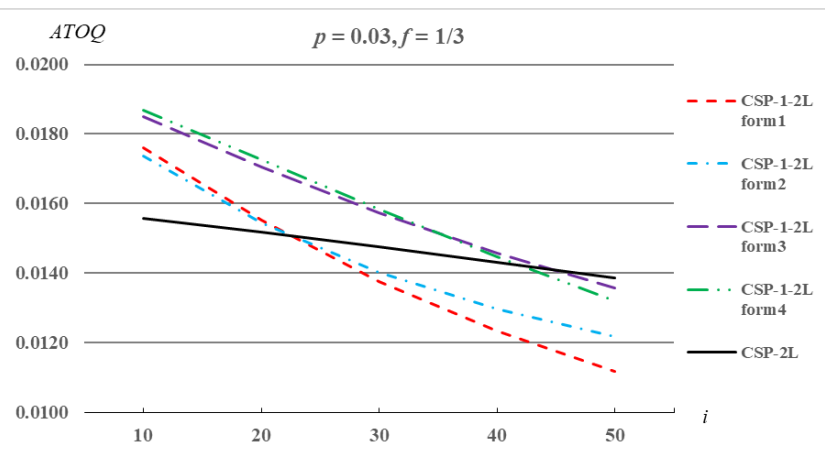

(h)

Figure 5. The $A T O Q$ values of the CSP-1-2L and the CSP-2L plans when $p=0.03$.

It can be seen from Figure 3 to Figure 5 that, in the case of $p$, the levels are low $(0.008, \mathrm{c}, \mathrm{d})$ and moderate $(0.01, \mathrm{e}, \mathrm{f})$, the $A T O Q$ of the CSP-2L are less than those of the CSP-1-2L in all cases. In the case of $p$ is at a high level $(0.03, \mathrm{~g}, \mathrm{~h})$, the $A T O Q$ of the CSP-2L is less than those of the CSP-1-2L only in cases of $i=10,20$ and 30 and $i=10$ and 20 for $r=2$ and 3 , respectively.

This means that for all sets of $i$ and $r$ values when the probability of a unit produced by the process being nonconforming of both lines are at low or moderate levels, and for all sets of $r$ and $i$ are at low values when the probability of a unit produced by the process being nonconforming of both lines is at a high level, the CSP-2L yields better product quality than those of the CSP-1-2L.

\section{Conclusion}

In this paper, the new continuous sampling plan was designed for the inspection of two production lines, which are independent at the same time, namely CSP-2L. The CSP-2L has given priority to the production line that is inspection at $100 \%$ inspection phase more than the production line that is inspection at sampling inspection phase and defines the probability of a unit produced by the process being nonconforming of the first production line is not less than the second production line. Moreover, the formulas to measure the performance of the CSP-2L such as the average total fraction inspected (ATFI) and the average total outgoing quality (ATOQ) are derived using a Markov chain, assuming that the production process is under statistical control.

In testing the accuracy of the formulas to measure the performance of the CSP-2L uses the percentage difference of the ATFI values (\%dif_ATFI) and the percentage difference of the $A T O Q$ values (\%dif_ATOQ). If \%dif_ATFI and $\%$ dif_ATOQ are less than or equal to $2 \%$, then the formulas will be accepted to be accurate [11]. The test results showed that, \%dif ATFI and $\%$ dif_ATOQ were found to agree within $2 \%$ in all cases. Therefore, the formulas to measure the performance of the CSP-2L are accurate.

The comparison results of the $A T O Q$ values between the CSP-1-2L and the CSP-2L plans showed that, for all sets of $i$ and $r$ values when $p$ are at low or moderate levels, and for all sets of $r$ and $i$ are at low values when $p$ is at a high level, the CSP-2L yields better product quality than those of the CSP-1-2L. 


\section{Discussion}

The advantage of the CSP-2L plan is that it has reduced the number of defective product units that have passed, resulting in higher quality of the products when compare with the CSP-1-2L plan when the probability of a unit produced by the process being nonconforming of both lines are low or moderate. However, it will also increase the number of inspection units. As a manufacturer that considers operating costs as the primary factor, if the number of inspection units increases then the operating costs will be higher. So, the selection of plan for inspection has to be based on the aims of the manufacturer. In the case of the manufacturer who need the high quality of production and low operating costs, this is possible under the CSP-2L conditions. At present, there is nothing designed to solve this objective. Therefore, the aforementioned objective will be a way to design a new plan in the future. So, in the future research, the authors are interested in sampling plan that can reduce operating costs and make high quality of production at the same time.

\section{Acknowledgments}

This study was fully supported by Research and Technology Transfer Affairs of Khon Kaen University and the author thanks the reviewers and the editor for their valuable comments and suggestions.

\section{References:}

[1] Abderrahman Rhouzali, Benayad Nsiri, Mounia Miyara, Mohamed Abid, Method Of Modeling Of The Control Systems Adapted To The Skills Production Systems, International Journal of Circuits, Systems and Signal Processing, Vol. 13, 2019, pp. 385-390.

[2] Guo-cheng Niu and Zhen Hu, Evaluation and Health Status Prediction Method of Beer Filling Production Line Based on Data Mining Technology, International Journal of Circuits, Systems and Signal Processing, Vol. 13, 2019, pp. 306-311,

[3] Yaling Qin and Dequan Yue, A Perishable Production Inventory System with Service Time and Its Performance Evaluation, International Journal of Circuits, Systems and Signal Processing, Vol. 13, 2019, pp. 148-155.

[4] H. F. Dodge, A Sampling inspection plan for continuous production, Annals of Mathematical Statistics, Vol. 14, No. 3, 1943, pp. 264-279.
[5] H. F. Dodge and M. N. Torrey, Additional Continuous Sampling Inspection Plans, Industrial Quality Control. Vol. 7, No. 5, 1951, pp. 7-12.

[6] G. J. Lieberman and H. Solomon, Multi-Level Continuous Sampling Plans, Annals of Mathematical Statistics. Vol. 26, No. 4, 1955, pp. 686-704.

[7] K. Govindaraju and S. Balamurali, Tightened single-level continuous sampling plan, Journal of Applied Statistics, Vol. 25, No. 4, 1998, pp. 451-461.

[8] S. Balamurali and K. Subramali, Modified CSP-C Continuous Sampling plan for Consumer Protection, Journal of Applied Statistics, Vol. 31, No. 4, 2004, pp. 481-494.

[9] P. Guayjarernpanishk and T. Mayureesawan, The Design of Two-Level Continuous Sampling Plan MCSP-2-C, Journal of Applied Mathematical Sciences, Vol. 6, No. 90, 2012, pp. 4483-4495.

[10] P. Guayjarernpanishk, The Fractional Sampling Plan for Continuous Production Line, Far East Journal of Mathematical Sciences, Vol. 84, No. 2, 2014, pp. 199-217.

[11] P. Guayjarernpanishk, The Design of Continuous Sampling Plan G-TF-CSP, WSEAS Transactions on Mathematics, Vol. 18, No. 40, 2019, pp. 319-325.

[12] S. Karlin, A First Course in Stochastic Processes, Academic Press, 1996.

[13] S. M. Ross, Stochastic Processes, $2^{\text {nd }}$ ed., John Wiley \& Sons, Inc., 1996.

[14] K. S. Stephens, The Handbook of Applied Acceptance Sampling Plans, Procedures, and Principles, American Society for Quality, 2001.

[15] D. C. Montgomery, Introduction to Statistical Quality Control, $6^{\text {td }}$ ed., John Wiley \& Sons, Inc., 2009.

[16] E. G. Schilling and D. V. Neubauer, Acceptance Sampling in Quality Control, $2^{\text {nd }}$ ed., Taylor \& Francis Group, 2009.

[17] T. Mayureesawan and P. Sudasna-Na-Ayudthaya, A CSP-1-2L Sampling Plan for Inspection of Two Continuous Production Lines, Journal of Research in Engineering and Technology. Vol. 2, No. 4, 2005, pp. 303-320.

[18] Stephens, K. S., "How to Perform Continuous Sampling (CSP)," Vol. 2, ASQC Basic References in Quality Control, Statistical Techniques, American Society for Quality Control, Milwaukee, WI, 1979.

[19] Course Note Stats 325, Stochastic Processes, Department of Statistics, University of Auckland, New Zealand, 2014, pp. 149-177.

[20] S. W. Roberts, States of Markov chains for evaluating continuous sampling plans, Transactions of the 17th Annual All Day Conference on Quality Control, Metropolitan Section, ASQC, and Rutgers University, New Brunswick, NJ, 1965, pp.106-111.

[21] H. A. Lasater, On the robustness of a class of continuous sampling plans under certain types of process models, PhD Dissertation, Rutgers University, New Brunswick, NJ, 1970. 


\section{Appendix}

Derivation of Performance Measures of the CSP-2L

At line 1: from the first and second conditions of the steady-state probabilities $\mathrm{P}\left(S_{n}\right)$ and relations from Table 1, we get

$$
\begin{aligned}
& \mathrm{P}\left(\mathrm{A}_{0}\right)=p_{1} \sum_{j=0}^{i_{1}} P\left(A_{j}\right), \\
& \mathrm{P}\left(\mathrm{A}_{j}\right)=\frac{q_{1}^{j}}{1-q_{1}^{i_{1}}} P\left(A_{0}\right) ; j=1,2, \ldots, i_{1}, \\
& \mathrm{P}\left(f_{1} \mathrm{~N}_{0}\right)+\mathrm{P}\left(f_{1} \operatorname{In}_{0}\right)+\mathrm{P}\left(f_{1} \operatorname{Id}_{0}\right) \\
& =\frac{1-q_{2}^{i_{2}}}{q_{2}^{i_{2}}} \frac{q_{1}^{i_{1}}}{1-q_{1}^{i_{1}}} P\left(A_{0}\right), \\
& \mathrm{P}\left(f_{1} \mathrm{~N}_{k}\right)+\mathrm{P}\left(f_{1} \operatorname{In}_{k}\right)+\mathrm{P}\left(f_{1} \operatorname{Id}_{k}\right) \\
& =\frac{q_{2}^{k}}{q_{2}^{i_{2}}} \frac{q_{1}^{i_{1}}}{1-q_{1}^{i_{1}}} P\left(A_{0}\right) ; k=1,2, \ldots, i_{2}, \\
& \mathrm{P}\left(f_{1} \mathrm{~N}_{l-1}^{\prime}\right)+\mathrm{P}\left(f_{1} \operatorname{In}_{l}^{\prime}\right)+\mathrm{P}\left(f_{1} \operatorname{Id}_{l}^{\prime}\right) \\
& =\frac{1}{f_{1}} \frac{q_{1}^{i_{1}}}{1-q_{1}^{i_{1}}} P\left(A_{0}\right) ; l=1,2, \ldots, m .
\end{aligned}
$$

From the third condition, we get

$$
\begin{aligned}
& \mathrm{P}\left(\mathrm{A}_{0}\right)+\sum_{j=1}^{i_{1}} \mathrm{P}\left(\mathrm{A}_{j}\right)+\mathrm{P}\left(f_{1} \mathrm{~N}_{0}\right)+\mathrm{P}\left(f_{1} \operatorname{In}_{0}\right)+\mathrm{P}\left(f_{1} \mathrm{Id}_{0}\right) \\
& +\sum_{k=1}^{i_{2}} \mathrm{P}\left(f_{1} \mathrm{~N}_{k}\right)+\mathrm{P}\left(f_{1} \operatorname{In}_{k}\right)+\mathrm{P}\left(f_{1} \operatorname{Id}_{k}\right) \\
& +\sum_{l=1}^{m} \mathrm{P}\left(f_{1} \mathrm{~N}_{l-1}^{\prime}\right)+\mathrm{P}\left(f_{1} \operatorname{In}_{l}^{\prime}\right)+\mathrm{P}\left(f_{1} \operatorname{Id}_{l}^{\prime}\right)=1 .
\end{aligned}
$$

From equations (11) to (14), it can be written (10) as

$$
\begin{aligned}
& \mathrm{P}\left(\mathrm{A}_{0}\right) \\
& =\frac{f_{1} p_{1} p_{2} q_{2}^{i_{2}}\left(1-q_{1}^{i_{1}}\right)}{f_{1} p_{2} q_{2}^{i_{2}}\left(1-q_{1}^{i_{1}}\right)+f_{1} p_{1} q_{1}^{i_{1}}\left(1-q_{2}^{i_{2}}\right)+m p_{1} p_{2} q_{1}^{i_{1}} q_{2}^{i_{2}}} .
\end{aligned}
$$

When replacing equation (11) to (14) with equation (15), we get

$$
\begin{aligned}
& \mathrm{P}\left(\mathrm{A}_{j}\right) \\
& =\frac{f_{1} p_{1} p_{2} q_{1}^{j} q_{2}^{i_{2}}}{f_{1} p_{2} q_{2}^{i_{2}}\left(1-q_{1}^{i_{1}}\right)+f_{1} p_{1} q_{1}^{i_{1}}\left(1-q_{2}^{i_{2}}\right)+m p_{1} p_{2} q_{1}^{i_{1}} q_{2}^{i_{2}}} \\
& ; j=1,2, \ldots, i_{1}, \\
& \mathrm{P}\left(f_{1} \mathrm{~N}_{0}\right)+\mathrm{P}\left(f_{1} \mathrm{In}_{0}\right)+\mathrm{P}\left(f_{1} \mathrm{Id}_{0}\right) \\
& =\frac{f_{1} p_{1} p_{2} q_{1}^{i_{1}}\left(1-q_{2}^{i_{2}}\right)}{f_{1} p_{2} q_{2}^{i_{2}}\left(1-q_{1}^{i_{1}}\right)+f_{1} p_{1} q_{1}^{i_{1}}\left(1-q_{2}^{i_{2}}\right)+m p_{1} p_{2} q_{1}^{i_{1}} q_{2}^{i_{2}}}, \\
& \mathrm{P}\left(f_{1} \mathrm{~N}_{k}\right)+\mathrm{P}\left(f_{1} \mathrm{In}_{k}\right)+\mathrm{P}\left(f_{1} \mathrm{Id}_{k}\right) \\
& =\frac{f_{1} p_{1} p_{2} q_{1}^{i_{1}} q_{2}^{k}}{f_{1} p_{2} q_{2}^{i_{2}}\left(1-q_{1}^{i_{1}}\right)+f_{1} p_{1} q_{1}^{i_{1}}\left(1-q_{2}^{i_{2}}\right)+m p_{1} p_{2} q_{1}^{i_{1}} q_{2}^{i_{2}}} \\
& \quad ; k=1,2, \ldots, i_{2},
\end{aligned}
$$

$$
\begin{aligned}
& \mathrm{P}\left(f_{1} \mathrm{~N}_{l-1}^{\prime}\right)+\mathrm{P}\left(f_{1} \operatorname{In}_{l}^{\prime}\right)+\mathrm{P}\left(f_{1} \operatorname{Id}_{l}^{\prime}\right) \\
& =\frac{p_{1} p_{2} q_{1}^{i_{1}} q_{2}^{i_{2}}}{f_{1} p_{2} q_{2}^{i_{2}}\left(1-q_{1}^{i_{1}}\right)+f_{1} p_{1} q_{1}^{i_{1}}\left(1-q_{2}^{i_{2}}\right)+m p_{1} p_{2} q_{1}^{i_{1}} q_{2}^{i_{2}}} \\
& \quad ; l=1,2, \ldots, m .
\end{aligned}
$$

Let

$$
\begin{aligned}
& \mathrm{P}\left(100_{1}\right)=\sum_{j=0}^{i_{1}} P\left(A_{j}\right) \\
& =\frac{f_{1} p_{2} q_{2}^{i_{2}}\left(1-q_{1}^{i_{1}}\right)}{f_{1} p_{2} q_{2}^{i_{2}}\left(1-q_{1}^{i_{1}}\right)+f_{1} p_{1} q_{1}^{i_{1}}\left(1-q_{2}^{i_{2}}\right)+m p_{1} p_{2} q_{1}^{i_{1}} q_{2}^{i_{2}}} .
\end{aligned}
$$

$$
\begin{aligned}
& \mathrm{P}\left(\mathrm{S}_{1}\right)=\mathrm{P}\left(f_{1} \mathrm{~N}_{0}\right)+\mathrm{P}\left(f_{1} \operatorname{In}_{0}\right)+\mathrm{P}\left(f_{1} \mathrm{Id}_{0}\right) \\
& +\sum_{k=1}^{i_{2}} \mathrm{P}\left(f_{1} \mathrm{~N}_{k}\right)+\mathrm{P}\left(f_{1} \operatorname{In}_{k}\right)+\mathrm{P}\left(f_{1} \mathrm{Id}_{k}\right) \\
& +\sum_{l=1}^{m} \mathrm{P}\left(f_{1} \mathrm{~N}_{l-1}^{\prime}\right)+\mathrm{P}\left(f_{1} \operatorname{In}_{l}^{\prime}\right)+\mathrm{P}\left(f_{1} \operatorname{Id}_{l}^{\prime}\right) \\
& =\frac{p_{1} q_{1}^{i_{1}}\left[f_{1}\left(1-q_{2}^{i_{2}}\right)+m p_{2} q_{2}^{i_{2}}\right]}{f_{1} p_{2} q_{2}^{i_{2}}\left(1-q_{1}^{i_{1}}\right)+f_{1} p_{1} q_{1}^{i_{1}}\left(1-q_{2}^{i_{2}}\right)+m p_{1} p_{2} q_{1}^{i_{1}} q_{2}^{i_{2}}} .
\end{aligned}
$$

From equations (20) and (21), we can find the average number of units inspected under the 100\% inspection of line 1 or $u_{1}$ and the average number of units passed under the sampling inspection of line 1 or $v_{1}$ from

$$
\begin{aligned}
u_{1} & =\frac{\mathrm{P}\left(100_{1}\right)}{\mathrm{P}\left(f_{1} \operatorname{In}_{m}^{\prime}\right)+\mathrm{P}\left(f_{1} \operatorname{Id}_{m}^{\prime}\right)} \\
& =\frac{1-q_{1}^{i_{1}}}{p_{1} q_{1}^{i_{1}}} . \\
v_{1} & =\frac{\mathrm{P}\left(\mathrm{S}_{1}\right)}{\mathrm{P}\left(f_{1} \operatorname{In}_{m}^{\prime}\right)+\mathrm{P}\left(f_{1} \operatorname{Id}_{m}^{\prime}\right)} \\
& =\frac{f_{1}\left(1-q_{2}^{i_{2}}\right)+m\left(q_{2}^{i_{2}}-q_{2}^{i_{2}+1}\right)}{f_{1} p_{2} q_{2}^{i_{2}}} .
\end{aligned}
$$

At line 2: in a similar way to line 1 and relations from Table 2, we get

$\mathrm{P}\left(\mathrm{B}_{0}\right)$

$$
=\frac{f_{2} p_{1} p_{2} q_{1}^{i_{1}}\left(1-q_{2}^{i_{2}}\right)}{f_{2} p_{1} q_{1}^{i_{1}}\left(1-q_{2}^{i_{2}}\right)+f_{2} p_{2} q_{2}^{i_{2}}\left(1-q_{1}^{i_{1}}\right)+m p_{1} p_{2} q_{1}^{i_{1}} q_{2}^{i_{2}}},
$$

$\mathrm{P}\left(\mathrm{B}_{k}\right)$

$$
\begin{aligned}
= & \frac{f_{2} p_{1} p_{2} q_{1}^{i_{1}} q_{2}^{k}}{f_{2} p_{1} q_{1}^{i_{1}}\left(1-q_{2}^{i_{2}}\right)+f_{2} p_{2} q_{2}^{i_{2}}\left(1-q_{1}^{i_{1}}\right)+m p_{1} p_{2} q_{1}^{i_{1}} q_{2}^{i_{2}}} \\
& ; k=1,2, \ldots, i_{2}, \\
& \mathrm{P}\left(f_{2} \mathrm{~N}_{0}\right)+\mathrm{P}\left(f_{2} \operatorname{In}_{0}\right)+\mathrm{P}\left(f_{2} \operatorname{Id}_{0}\right) \\
= & \frac{f_{2} p_{1} p_{2} q_{2}^{i_{2}}\left(1-q_{1}^{i_{1}}\right)}{f_{2} p_{1} q_{1}^{i_{1}}\left(1-q_{2}^{i_{2}}\right)+f_{2} p_{2} q_{2}^{i_{2}}\left(1-q_{1}^{i_{1}}\right)+m p_{1} p_{2} q_{1}^{i_{1}} q_{2}^{i_{2}}},
\end{aligned}
$$




$$
\begin{aligned}
& \mathrm{P}\left(f_{2} \mathrm{~N}_{j}\right)+\mathrm{P}\left(f_{2} \operatorname{In}_{j}\right)+\mathrm{P}\left(f_{2} \operatorname{Id}_{j}\right) \\
& =\frac{f_{2} p_{1} p_{2} q_{1}^{j} q_{2}^{i_{2}}}{f_{2} p_{1} q_{1}^{i_{1}}\left(1-q_{2}^{i_{2}}\right)+f_{2} p_{2} q_{2}^{i_{2}}\left(1-q_{1}^{i_{1}}\right)+m p_{1} p_{2} q_{1}^{i_{1}} q_{2}^{i_{2}}} \\
& \quad ; j=1,2, \ldots, i_{1}, \\
& =\frac{\mathrm{P}\left(f_{2} \mathrm{~N}_{l-1}^{\prime}\right)+\mathrm{P}\left(f_{2} \operatorname{In}_{l}^{\prime}\right)+\mathrm{P}\left(f_{2} \operatorname{Id}_{l}^{\prime}\right)}{f_{2} p_{1} q_{1}^{i_{1}}\left(1-q_{2}^{i_{2}}\right)+f_{2} p_{2} q_{2}^{i_{2}}\left(1-q_{1}^{i_{1}}\right)+m p_{1} p_{2} q_{1}^{i_{1}} q_{2}^{i_{2}}} \\
& \quad ; l=1,2, \ldots, m .
\end{aligned}
$$

Let

$$
\begin{aligned}
& \mathrm{P}\left(100_{2}\right)=\sum_{k=0}^{i_{2}} \mathrm{P}\left(\mathrm{B}_{k}\right) \\
& =\frac{f_{2} p_{1} q_{1}^{i_{1}}\left(1-q_{2}^{i_{2}}\right)}{f_{2} p_{1} q_{1}^{i_{1}}\left(1-q_{2}^{i_{2}}\right)+f_{2} p_{2} q_{2}^{i_{2}}\left(1-q_{1}^{i_{1}}\right)+m p_{1} p_{2} q_{1}^{i_{1}} q_{2}^{i_{2}}} .
\end{aligned}
$$

$$
\begin{aligned}
& \mathrm{P}\left(\mathrm{S}_{2}\right)=\mathrm{P}\left(f_{2} \mathrm{~N}_{0}\right)+\mathrm{P}\left(f_{2} \operatorname{In}_{0}\right)+\mathrm{P}\left(f_{2} \operatorname{Id}_{0}\right) \\
& +\sum_{j=1}^{i_{1}} \mathrm{P}\left(f_{2} \mathrm{~N}_{j}\right)+\mathrm{P}\left(f_{2} \operatorname{In}_{j}\right)+\mathrm{P}\left(f_{2} \operatorname{Id}_{j}\right) \\
& +\sum_{l=1}^{m} \mathrm{P}\left(f_{2} \mathrm{~N}_{l-1}^{\prime}\right)+\mathrm{P}\left(f_{2} \operatorname{In}_{l}^{\prime}\right)+\mathrm{P}\left(f_{2} \operatorname{Id}_{l}^{\prime}\right) \\
& =\frac{p_{2} q_{2}^{i_{2}}\left[f_{2}\left(1-q_{1}^{i_{1}}\right)+m p_{1} q_{1}^{i_{1}}\right]}{f_{2} p_{1} q_{1}^{i_{1}}\left(1-q_{2}^{i_{2}}\right)+f_{2} p_{2} q_{2}^{i_{2}}\left(1-q_{1}^{i_{1}}\right)+m p_{1} p_{2} q_{1}^{i_{1}} q_{2}^{i_{2}}} .
\end{aligned}
$$

From equations (24) and (25), we can find the average number of units inspected under the $100 \%$ inspection of line 2 or $u_{2}$ and the average number of units passed under the sampling inspection of line 2 or $v_{2}$ from

$$
\begin{aligned}
u_{2} & =\frac{\mathrm{P}\left(100_{2}\right)}{\mathrm{P}\left(f_{2} \operatorname{In}_{m}^{\prime}\right)+\mathrm{P}\left(f_{2} \mathrm{Id}_{m}^{\prime}\right)} \\
& =\frac{1-q_{2}^{i_{2}}}{p_{2} q_{2}^{i_{2}}} \\
v_{2} & =\frac{\mathrm{P}\left(\mathrm{S}_{2}\right)}{\mathrm{P}\left(f_{2} \operatorname{In}_{m}^{\prime}\right)+\mathrm{P}\left(f_{2} \mathrm{Id}_{m}^{\prime}\right)} \\
& =\frac{f_{2}\left(1-q_{1}^{i_{1}}\right)+m\left(q_{1}^{i_{1}}-q_{1}^{i_{1}+1}\right)}{f_{2} p_{1} q_{1}^{i_{1}}}
\end{aligned}
$$

Then we can get the performance measures of the CSP-2L which are given from equations (22), (23), (26) and (27).

\section{Creative Commons Attribution License 4.0 (Attribution 4.0 International, CC BY 4.0)}

This article is published under the terms of the Creative Commons Attribution License 4.0

https://creativecommons.org/licenses/by/4.0/deed.en_US 